\begin{tabular}{|c|c|c|c|c|c|c|c|}
\hline 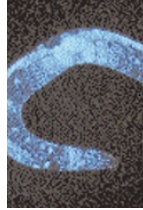 & $\begin{array}{l}\text { WormBase } \\
\text { Internet site plans } \\
\text { to round up } \\
\text { nematode data } \\
\text { p425 }\end{array}$ & $\frac{\pi}{1+1}$ & $\begin{array}{l}\text { Spanish jobs } \\
\text { New structure for } \\
\text { university } \\
\text { recruitment } \\
\text { p425 }\end{array}$ & $\frac{1}{2}$ & $\begin{array}{l}\text { Shell collection } \\
\text { Giant success for } \\
\text { tortoise rescue } \\
\text { programme } \\
\text { p426 }\end{array}$ & 18 & $\begin{array}{l}\text { Bio-systems } \\
\text { Sharing simple } \\
\text { thoughts may solve } \\
\text { complex problems } \\
\text { p427 }\end{array}$ \\
\hline
\end{tabular}

\title{
Safety concerns force NASA to condemn satellite to fiery end
}

\section{Washington}

The US space agency NASA last week chose safety over science and decided to send the nine-year-old Compton Gamma Ray Observatory to an early death.

The 17-tonne satellite suffered a gyroscope failure in December that compromised its ability to maintain a safe orbit (see Nature 403, 232; 2000). It will be manoeuvred to burn up in the atmosphere over the Pacific Ocean on about 3 June.

Engineers at the Goddard Space Flight Center in Maryland, which operates the spacecraft, had found a way to control it even if all three onboard gyroscopes were to fail. But the new technique was estimated to be eight times less reliable than manoeuvring the satellite with gyros.

NASA fears that if the satellite fell uncontrolled, it would drop pieces weighing a tonne or more in an unpredictable path that could pass over populated areas. It could come down within three years, and the chance of a human fatality would be one in a thousand.

That was too much for agency science chief Edward Weiler, who made the decision to bring down the spacecraft. "I simply cannot justify more science in a mission that's already met its prime scientific objectives by increasing the risk of loss of human life by a factor of eight," he said at a press conference last week. Guiding the re-entry increases the safety factor dramatically, so that the risk of a fatality becomes one in four million.

Weiler insisted that cost was not a factor in his decision, as operation of the observatory, now running in a reduced mode, has been cut to less than $\$ 4$ million a year.

"We will lose science, there is no question about it," Weiler admitted. Compton project scientist Neil Gehrels said he was "personally profoundly disappointed" in the final verdict.

"The scientists were certainly pushing hard to see if we could eke out a few more months or years," said Gehrels. "But I respect the difficulty of this decision and the importance of safety."

No other spaceborne gamma ray telescope has Compton's all-sky view, and it is still discovering the enigmatic Gamma Ray Bursts (GRBs) at the rate of one a day. But

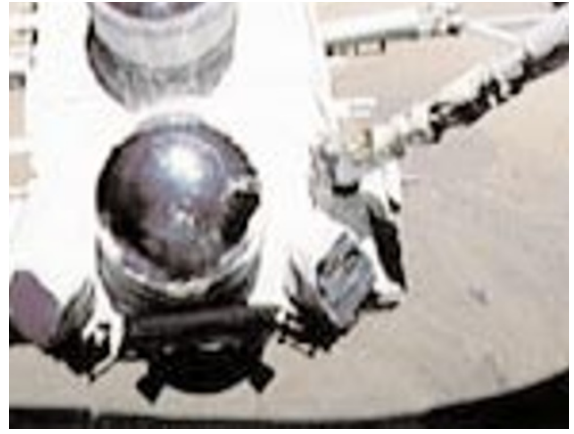

In a spin: gyroscope failure has doomed the Compton Observatory, released (above) in 1991.

astronomers will soon have a new spacecraft specially designed to study GRBs.

The low-cost HETE-2 satellite, which was to have been launched earlier this year (see Nature 403, 583; 2000) is expected to reach orbit in June or July.

HETE is expected to find no more than one to three GRBs a week, and its field of view will be limited. But, says principal investigator George Ricker of the Massachusetts Institute of Technology, ground-based observers should be better able to follow up rapidly on burst detections, as all HETE's observations will be in the night-time sky.

HETE's summer Pegasus launch replaces another small science mission, the High Energy Solar Spectroscopic Imager (HESSI), which last week fell victim to the latest mishap at NASA's Jet Propulsion Laboratory. A routine prelaunch vibration test went awry, and the spacecraft was briefly shaken with ten times the force it was supposed to receive, damaging its solar arrays and setting back its launch date by at least six months.

"It was a standard test on a standard facility — just bad luck," says Peter Harvey, HESSI project manager at the University of California at Berkeley. NASA will form a committee to determine the cause of the accident - an all-too-familiar exercise at the space agency these days. Tony Reichhardt

\section{Software error 'caused Mars lander crash'}

\section{Washington}

The Mars Polar Lander that disappeared without a trace last December probably crashed into the planet due to a software error, according to a report to be released this week. A committee chaired by John Casani, former chief engineer at the Jet Propulsion Laboratory, which managed the doomed spacecraft, identified the programming error after examining several possible accident causes.

The lander's legs had microswitches that were to have signalled onboard engines to shut down when the legs made contact with the surface. But the switches sensed a jolt when the landing legs unfolded during the descent through the Martian atmosphere, and faulty software failed to tell the difference between the jolt and a real landing. As a result, the engines shut off prematurely, and the lander fell the rest of the way to the surface with no retrorockets to soften the blow.

A second panel of outside experts, chaired by former aerospace executive Thomas Young, identified more generic problems, as have other reports issued in recent weeks, which have criticized NASA for poor management and underfunding of missions ranging from the space shuttle to the Mars Climate Orbiter that also failed last autumn.

Tony Spear, a former manager of the successful Mars Pathfinder project who reviewed NASA's 'better, faster, cheaper' missions for its administrator Daniel Goldin, said at a recent NASA Advisory Council meeting that "we should slow the rate of missions until we understand how to do them."

NASA and JPL are already planning to overhaul the Mars programme as a result of the reports, according to sources. The changes are likely to include more intense supervision of the programme at NASA headquarters, less emphasis on sample return as the main focus of the Mars effort, and using small missions to conduct a reconnaissance of the Martian surface before sending large landers. 